\title{
Referral and collaboration between South African psychiatrists and religious or spiritual advisers: Views from some psychiatrists
}

\author{
A B R Janse van Rensburg, ${ }^{1} \mathrm{MB} \mathrm{ChB}, \mathrm{MMed}, \mathrm{FCPsych}(\mathrm{SA}), \mathrm{PhD} ;$ M Poggenpoel, ${ }^{2} \mathrm{PhD}, \mathrm{RN}$; \\ C P Szabo, ${ }^{1}$ MB BCh, MMed, FCPsych (SA), PhD, MSc (Bio-Ethics); C P H Myburgh, ${ }^{3}$ BSc Hon, MCom, DEd \\ ${ }^{1}$ Department of Psychiatry, University of the Witwatersand, Johannesburg, South Africa \\ ${ }^{2}$ Department of Nursing, University of Johannesburg, South Africa \\ ${ }^{3}$ Department of Educational Psychology, University of Johannesburg, South Africa
}

Corresponding author: A B R Janse van Rensburg (bernardj@gpg.gov.za)

\begin{abstract}
Background. Referral between psychiatrists and spiritual workers (e.g. Christian pastoral care workers, traditional healers, imams, rabbis and others) in the heterogeneous South African (SA) society is complicated and requires investigation to establish appropriate norms.

Objective. To capture the views of some local psychiatrists on referral and collaboration between SA psychiatrists and religious or spiritual advisers.

Methods. This explorative qualitative study involved in-depth, semistructured interviews with 13 local academic psychiatrists selected through purposive sampling. Each participant had a single interview with the aim of exploring themes related to the referral and collaboration process between psychiatrists and spiritual advisers. Theme content analysis of interview transcripts was done. Results for one of the six identified themes are reported; other results are reported elsewhere.

Results. Within the theme 'referral and collaboration between psychiatrists and spiritual professionals', three subthemes were identified: facilitating appropriate referral and intervention for individual users; information sharing and mutual awareness between disciplines; and addressing stigmatisation of users with psychiatric conditions.

Conclusion. Dialogue between psychiatrists and religious or spiritual advisers should be developed on an individual practitioner and facility basis, as well as on an organised basis between representative societies. The process of formalising a relationship between local psychiatrists and different spiritual workers may, however, still have some way to go.
\end{abstract}

S Afr J Psych 2014;20(2):40-45. DOI:10.7196/SAJP.533

$\therefore$.. [the] two neighbours [psychiatry and religion] ... should be on very good terms, but, due to a long-forgotten episode over the niggle about the size of the fence, have fallen out. It is high time that commonalities are ascertained and shared and differences are put to one side. ${ }^{[1]}$

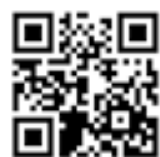

In the traditionally secular fields of health, mental health and psychiatry, the question can be asked why we even consider the topic of religion and spirituality. However, the significant roles that culture, religion and spirituality play in communities underline their importance. In recent censuses, the vast majority of South Africans - as elsewhere in the world - report themselves to be religiously affiliated, ${ }^{[2,3]}$ and it is part of the daily experience of psychiatrists to contend with the extent to which religion and spirituality play a role in the lives of their patients. Morris ${ }^{[4]}$ noted the importance of achieving a sociological and anthropological understanding of spirituality and religions, and other authors have noted that the unique approach of each faith tradition as it relates to health, mental health and clinical medicine should be understood and explored..$^{[5-14]}$

Psychiatry has long been practised within a multidisciplinary environment, with intervention teams involving nursing professionals, psychologists, occupational therapists and social workers. Since the 1980s, however, psychiatry has been taught to undergraduate medical students and postgraduate registrars from the perspective of Engel's 'biopsychosocial' model of assessment and care. ${ }^{[15,16]}$ If we are to add spirituality to the dimensions of this model of teaching and practice, a second question arises: How should religious or spiritual advisers (e.g. priests, traditional healers, imams, rabbis and others) be integrated into existing multidisciplinary teams of clinical workers?

The South African (SA) Constitution affirms that no single faith tradition can be considered to have preference over others, particularly in public settings such as schools, correctional facilities and hospitals ${ }^{[17]}$ - although the Freedom Park Trust, for example, pointed out in a discussion on spirituality and the secular state that the restoration of indigenous African forms of spirituality is still needed, following their liberation from 'colonial spirituality'. ${ }^{[18]}$ Colonial spirituality, in this discussion, was described as being of a religious type and largely Christian, which in colonial states comprised a close marriage between church and state, and which pursued the enterprise 
of 'conquering the indigenous epistemological space. From these statements, a third important group of questions about the agenda, definition of terms, disciplinary boundaries and the scope of practice of the different multidisciplinary caregivers needs to be addressed.

The overlap and differences between definitions of culture, religion and spirituality should be considered a reasonable starting point. A recent local study by Hassim and Wagner, ${ }^{[19]}$ commented on by Rashed ${ }^{[20]}$ considered the cultural context in psychopathological formulation. It found that: health and behaviour are dependent, at least in part, on culture; psychopathology may also be understood as a social construct; culture has an influence on psychopathology, regardless of its aetiology; diagnostic classes do not adequately consider operational definitions; and a greater focus on hermeneutic perceptivity in appreciating cultural dynamics in psychopathology would benefit clinical assessment.

A definition of religion usually alludes to the outward expression of spiritual beliefs' that have been organised into integrated systems of doctrine and institutionalised structures. ${ }^{[21]}$ For the purposes of this introduction, it suffices to say that a definition of spirituality should at least include the notions of a 'quality', a 'journey', a 'relationship' and a 'capacity.' ${ }^{[11,22-23]}$ The World Psychiatric Association, ${ }^{[24]}$ for example, refers to a definition of spirituality, as quoted by Schneiders, ${ }^{[25]}$ as: 'Spirituality comprises awareness, an experience of something that surpasses ordinary observation and perception. It is not simply an abstract idea, or theory. It includes an element of advancing movement, a quest. It is not a once-only experience or event. It contains an element of integration, unification and, consequently, unity. Spirituality is holistically orientated.' Kourie ${ }^{[26]}$ noted that 'secular spirituality' should instead be considered as a postmodern approach to the problem of definition and territory, through which spirituality would then be concerned with the everyday issues of life, rejecting dualistic supernaturalism and atheistic nihilism, as well as the bifurcation of the sacred and the secular.

Spirituality and religion have increasingly been considered and reported on in the international medical and psychiatric literature over the past two decades. ${ }^{[27,28]}$ According to Pargament and Lomax, ${ }^{[29]}$ 'the last 20 years have witnessed a sharp rise of scientific interest in the links between religion and psychological functioning. This trend was also confirmed by a recent qualitative review of the medical literature on the role of spirituality in psychiatry. ${ }^{[30]}$ Different opinions exist on whether a spiritual dimension should be considered in addition to the current biopsychosocial approach used in medical and psychiatric practice and training. ${ }^{[31-34]}$ Arguing for its inclusion, Bathgate ${ }^{[35]}$ referred to Lakoff and Johnson's ${ }^{[36]}$ statement: 'However, once the mind is taken to be disembodied, the gap between mind and world becomes unbridgeable'. He suggested that, through considering the role of spirituality, psychiatrists may contribute to the generation of more hopeful and empowering stories of intervention for patients. ${ }^{[35]}$

Different opinions also exist about how - and if - religious or spiritual workers, such as traditional African health practitioners, should be regarded in terms of a team of caregivers. In a review of the SA literature on the documented interface of alternative and traditional health practices with mental healthcare in SA since the 1950s, Janse van Rensburg ${ }^{[37]}$ noted that some authors saw traditional health practitioners as psychotherapists, ${ }^{[38,39]}$ while others referred to African cultural beliefs as being a religious and spiritual practice. ${ }^{[40,41]}$ The latter noted that the role of traditional healers is 'being priests before healers', with an intermediary function between the people and their ancestors: 'From the very outset, the traditional healer is directed by the spirit world of the ancestors. His powers arise out of this contact with the spirits - he is expected to have supernatural powers and to use them for healing purposes. ${ }^{\text {'[42] }}$ The SA Medical Association (SAMA), among others, also explored this question and published a review of the work of a task team on the proposed collaboration between traditional healers and medical practitioners. ${ }^{[43]}$ Based on the principle that the patient is pivotal in the healthcare equation and that traditional health practitioners play an important role in Africa, SAMA expressed the view that some degree of cooperation between the two systems is desirable.

However, most of the international medical literature reflects North American and European authors' views, in which the discussion of the role of a religious or spiritual adviser in multidisciplinary health teams refers mostly to a Christian pastoral counsellor with additional experience or qualifications in clinical settings.

Inclusion of a religious or spiritual adviser in SA clinical mental healthcare teams will, however, pose the considerable challenge of how to translate these inputs correctly in the context of a heterogeneous, multicultural and multireligious society. It may also present logistical challenges that are potentially politically charged because, for example, it would be unfeasible to appoint spiritual or religious advisers from every faith or tradition to every hospital on a formal basis. Despite SA's well-known cultural and religious diversity, no formal guidelines on the referral and collaboration between psychiatrists and spiritual advisers, or on what training and experience in clinical conditions are needed for religious or spiritual advisers to qualify for such collaboration, have been drawn up yet.

In the context of this changing environment, we designed a broad, explorative, qualitative enquiry to capture the views and experiences of SA psychiatrists on the role of spirituality in psychiatric practice and training, including how to refer to and collaborate with spiritual advisers on religious and spiritual matters. ${ }^{[44]}$ The broader objectives of the study included to explore, analyse and describe the respondents' views and experiences on this topic, and to interpret these in the context of the local and international medical literature. Some of the results of the interview content from this study have been published elsewhere. ${ }^{[45]}$ Themes from the literature content from this study included: (i) orientation in terms of spirituality and religion in psychiatry; (ii) reality of spirituality and religion for practitioners and users; (iii) routine assessment of spirituality and religion in psychiatry; (iv) training of spirituality in psychiatry; $(v)$ scope and boundaries of spirituality in psychiatry; and (vi) referral and collaboration between psychiatrists and spiritual professionals. ${ }^{[45]}$ At the same time as results on one of the other themes, 'training of spirituality in psychiatry', were also reported elsewhere, ${ }^{[46]}$ a model on the role of defined spirituality in local specialist psychiatric practice and training, derived from both the literature and interview content, was proposed. ${ }^{[47]}$

The objective of this article is to describe in more detail the findings of our broader qualitative study with a focus on the sixth main theme identified: 'referral and collaboration on spirituality' between psychiatrists and spiritual advisers/workers. 


\section{Methods}

The study was designed as an explorative, phenomenological, theorygenerating qualitative investigation, the methods of which have been reported in full elsewhere. ${ }^{[44-47]}$ In-depth, semistructured interviews were conducted with a series of academic specialist psychiatrists affiliated to the University of the Witwatersrand, Johannesburg. ${ }^{[48]}$ A purposive sample for the interviews was drawn from this group, who were all appointed to the Department of Psychiatry and who all held clinical positions at sites within the academic complexes serving the university. About 40 psychiatrists were attached to these services when the sample was drawn. Ethical clearance for this study was granted by the ethics committee of the University of the Witswatersrand in 2007. Informed consent for participation was obtained from individual participants. In addition, the organised profession, as represented by the South African Society of Psychiatrists (SASOP) through its regional structures, was informed about the intent, scope and results of the study. ${ }^{[4-47]}$

\section{Data collection $^{[44-47]}$}

In-depth, semistructured interviews provided knowledge about participants' experience of, and views on, the role of spirituality in specialist psychiatric practice and training. Janse van Rensburg conducted all the interviews in English, and no problems were experienced with the articulation of concepts or with language. Only one interview per participant was conducted, and the duration of each interview was about 1.3 hours on average. Participants were presented with one open-ended question: 'What is your experience of and view on the role of spirituality in specialist psychiatric practice and training?' During the actual interviews, concepts were explored and elaborated on only through non-directive techniques such as reflecting and paraphrasing. Each interview was audio-taped and transcribed, while field notes were compiled after each interview. Interviews were conducted until data saturation was reached, which was regarded as the point at which no new elements from the subsequent interview content were identified.

\section{Data analysis $^{[44-47]}$}

Thematic content analysis through coding of data was used. ${ }^{[49]}$ Open coding was done for analysis of the thematic content, referring to the creation of categories relating to segments of text, and was aimed at expressing data in the form of concepts. ${ }^{[50]}$ Apart from the investigator (first author), a second independent coder was requested to analyse the interview transcripts. The final categories of concepts and themes from the interviews were confirmed after consensus was reached between the investigator and the second coder.

\section{Measures to ensure trustworthiness ${ }^{[44-47]}$}

This investigation was conducted considering credibility, transferability, dependability and confirmability, described by $\mathrm{Guba}^{[51]}$ as appropriate measures of trustworthiness for qualitative enquiries. Triangulation was incorporated, e.g. by including independent coding of the interview content in addition to the investigator's own coding. ${ }^{[49]}$

\section{Results}

After 13 interviews, no new elements were identified from the interview content and the data were considered to be saturated ${ }^{[44-47]}$
The participants' ages ranged from 33 to 71 years; six were men and seven were women; participants' professional experience, after qualifying as psychiatrists, ranged from 2 to 29 years; and most were employed at the time as senior, principal psychiatrists. ${ }^{[44-47]}$ Their stated personal religious or spiritual identifications included: discontinued religious ties, with currently only spiritual interests; being raised in an organised religious context, but with no current religious or spiritual affiliation or interest; continued serious and even strict organised religious affiliation with active participation; continued organised membership with extended spiritual orientation or awareness; and continued identification with original religious and cultural background, but currently with a more general spiritual awareness. $^{[44-47]}$

\section{Overview of interview content}

According to participants, awareness of spirituality, the capacity to self-reflect, and an open-minded approach towards spirituality should be facilitated in specialist psychiatric practice and training. ${ }^{[45]}$ Participants had diverse views and experiences on the role of spirituality in psychiatry, but all stated that spirituality should be considered in current specialist practice and training. ${ }^{[45]}$

After consensus was achieved about their description and order, six final categories of concepts were confirmed, namely: (i) orientation in terms of spirituality and religion in psychiatry; (ii) reality of spirituality and religion for practitioners and users; (iii) routine assessment of spirituality and religion in psychiatry; (iv) training of spirituality in psychiatry; $(v)$ scope and boundaries of spirituality in psychiatry; and ( $v i)$ referral and collaboration between psychiatrists and spiritual professionals. ${ }^{[4-47]}$ This last category is discussed in more detail in this article.

\section{Referral and collaboration between psychiatrists and spiritual professionals}

Within the sixth category of concepts identified from the interviews, three subcategories were identified: (i) facilitating appropriate referral and intervention for individual users; (ii) information sharing and mutual awareness between disciplines; and (iii) addressing stigmatisation of users with psychiatric conditions. ${ }^{[45]}$

\section{Facilitating appropriate referral and intervention ${ }^{[45]}$}

It may be difficult and logistically challenging to organise the liaison between specialist psychiatrists and spiritual workers into formalised referral systems, or to integrate them generally into the existing multidisciplinary mental healthcare team:

'It's such a problem. And how are you going to find a spiritual worker who is able to embrace absolutely every part of spirituality, with a vast difference of people in our community?'

'To me, spirituality is something separate from health workers as a parallel thing. I don't think you are going to create a job in a hospital, because then you need to create ... then I must hire an Anglican minister and a Muslim and a Jew and a traditional healer all to work in the hospital ... but why, because they aren't health workers?'

'I think not [a spiritual person on the multidisciplinary team]. I would think it would be more a referral thing. You know, for example we have a lot of patients who go for marital counselling with their 
pastor or the imam is involved in some way with the family, so we tend to use those.'

Information sharing and mutual awareness between disciplines ${ }^{[45]}$ Defining the relationship as a parallel process alongside each other (psychiatry/health and spirituality) may still be the practical approach, while acknowledging that health workers themselves may be from different world views and backgrounds, but responsible for their particular area of work in the first place:

'I think tradition goes both ways. We could teach them about psychoeducation, they could teach us and I think ... dialogue ... for example just even Psychiatry and Medicine in this hospital, we are so divided. And just opening up those channels of communication could really, really improve the situation ... so by opening up dialogue with different people of different ideas.'

The interface with spiritual workers presents the opportunity and challenge to establish a mutually informative collaboration where psychiatry has achieved a presence and acceptance or acknowledgement on the one hand, and confront and correct misperception and stigma in more fundamentalist religious perspectives where necessary, on the other:

'You know I think we were able to say: "Look, we don't like it when you do this and this and this" and they said: "We don't like it when you tell our patients not to come visit us" and that sort of thing. And I do think you can get a ... much better chance of getting a decent working relationship and try also to weed out some of the not-sogood practices on both sides. I don't think we are perfect either ...'

\section{Addressing stigmatisation of users with psychiatric conditions ${ }^{[45]}$}

Previous experiences and perceptions, however, are still the basis for continued ambivalence and conflicting views and feelings that psychiatrists have on how to interact practically with spiritual workers on the care of users. Knowledge of psychiatry and the benefits of pharmacological and psychological interventions, for example, should also be promoted among different groups of spiritual/religious workers:

'I think stigma and discrimination [represents] a huge problem and just in terms of the patients that we're seeing are so marginalised. But on the other hand I suppose if we could try to demarginalise our patients ...'

'I mean what I'm trying to say is accommodating spiritual beliefs to the extent of disadvantaging them from the benefits of other interventions. And yet one needs to balance that with not being imposing and you know, basically prescribing to people what they should be believing and practising. It's a delicate balance.'

Dialogue between the organised profession of psychiatry, for example SASOP, and representative bodies of organised spiritual/ religious workers may be a starting point:

'So I think it's a matter of engaging with them (e.g. traditional healers ... and other religious workers) and I think that one can engage at a systemic level with societies, councils and practitioner groups in terms of trying to look at standards of care and referral systems. And I think what would be necessary would be a lot of education on both sides, you know.

'I think it would be best if [communication] were to be done at an organisational level. I mean that doesn't deter us from doing it at an individual level which we've had to do already. Within the context of the unit we've engaged with many spiritual workers and it's been quite ... it hasn't been a problem.

\section{Discussion}

While the results of the broader, explorative, qualitative enquiry on the role of spirituality in psychiatry were reported on elsewhere, ${ }^{[44-47]}$ as noted above, the discussion in this article will focus in more detail on one of the main themes identified by this study, namely, the 'referral and collaboration on spirituality in psychiatry'.

A particular limitation of the broader qualitative study is that its findings cannot be generalised to other settings, since it was not designed to be representative of even the population of psychiatrists from which the sample was drawn. However, although only some psychiatrists from one university participated in these interviews, several pertinent points were made about the role of spirituality in psychiatry.

The problem of how a spiritual adviser will be able to embrace spirituality as it exists for all different religious and non-religious faith backgrounds in a multicultural society was raised by participants in this study, and doubt was expressed that spiritual advisers should be part of (mental) health teams, as they are not health workers per se.

The principle of referral was acknowledged, as was the fact that dialogue between psychiatrists and religious or spiritual advisers should be developed on an individual practitioner and unit basis, and on an organised basis between representative societies.

Overcoming stigma was noted as a priority, in that it would both clear up misinformation and discrimination and protect patients from unfounded, unsafe and prejudiced perceptions and practices.

The balance and ethics of not being prescriptive to patients about their spiritual and religious convictions, or the lack thereof, were emphasised.

Although Bulbulia and Laher, ${ }^{[52]}$ in a similar study using interviews with psychiatrists, subsequently reported on the role of Islam in perceptions of mental illness in a sample of Muslim psychiatrists based in Johannesburg, and while Padayachee and Laher ${ }^{[53]}$ reported on SA Hindu psychologists' perceptions of mental illness, this study of the views of our academic psychiatrists was the first SA study to explore in detail psychiatrists' views on the role of spirituality in specialist psychiatric practice and training. ${ }^{[44]}$

In considering how to implement a role for defined spirituality in health, mental health and psychiatry in the heterogeneous SA society, several points of view may have to be considered. For example, with reference to local African traditional healing practices, Ashforth ${ }^{[54]}$ alludes to attempts by proponents of indigenous knowledge systems to provide traditional African healing with scientific status, while contrasting it with a call made earlier by a prominent local black physician 'to stop romanticising the evil depredations of the sangoma in order to free patients from the tyranny of superstition. ${ }^{\text {'[5] }}$ In Ashforth's view, the relationship between traditional healing practices and science is incommensurable, implying that the differences between 'the two neighbours', as quoted earlier from Bhugra, ${ }^{[1]}$ may be somewhat more complicated that just 'a small niggle' over a boundary issue.

In a scenario where, on an organised basis, more active engagement between psychiatrists and religious or spiritual advisers is considered, 
possible activities may include: more structured communication between the representatives of these groups (e.g. through SASOP); exploring referral arrangements in a geographical catchment area context at facility or district level; and establishing forums for mental health education and for advocacy for patients with psychiatric conditions. A framework for referral and collaboration on spirituality in psychiatry may include: clarifying agendas and confirming definitions, terminology and scope of practice; establishing the role of culture, religion and spirituality in different communities; obtaining the different perspectives of particular faith traditions or belief systems on health and mental health; providing information on evidence-based management of serious psychiatric conditions (risk factors, symptoms, diagnoses, treatment) to spiritual advisers/ workers and to patients; and taking measures to ensure compliance, destigmatisation and optimal outcomes of psychiatric treatment. To date, on an organisational level, SASOP recently included the following statement on culture, mental health and psychiatry in their position statements on psychiatric care in the public sector:

'Culture, religion and spirituality should be considered in the current approach to the local practice and training of specialist psychiatrists. This should, however, be performed within the professional and ethical scope of the discipline, and all faith traditions and belief systems in the heterogeneous South African society should be respected and regarded equally. In the public sector domain, no preference for one particular tradition should be given over another, as a result of a practitioner or a dominant group being from the one tradition or the other. Building relationships of mutual trust and understanding will require training and health education initiatives aimed at psychiatric practitioners, their patients, carers and students, and cultural and religious practitioners whom patients and their carers may choose to consult. The protection of individuals with psychiatric conditions within traditional and other religious/spiritual healing systems, however, needs to be ensured and all forms of abuse in this context, or neglect and delay with regard to appropriate psychiatric care, should be identified and prevented. ${ }^{[56]}$

It should also be noted here that it appears that different faith traditions are not currently considered equally in terms of their role in the formal health sector. African traditional health practice, for example, seems to be awarded a disproportionately large space in this regard, as a controlling council has been legislated and constituted for African traditional health practitioners. ${ }^{[57]}$ Traditional healers in various scenarios have formally been elected to clinic committees, hospital boards, district health committees, and provincial and national advisory structures. Also, certain alternative health practitioners, such as Ayurveda, Chinese Medicine and Unani-Tibb practitioners, are already included in the Allied Health Professions Council of South Africa. ${ }^{[58]}$ However, while there is a long tradition of pastoral care counselling services and courses in SA, including postgraduate qualifications in practical theology, separate professional status for Christian pastoral care workers still has to be achieved. ${ }^{[59]}$

In this unequal situation in the SA health sector, it may therefore be appropriate to consider the question of the possible biomedical knowledge and clinical therapeutic skills that should be required from spiritual workers or advisers before they can be considered as potential members of a clinical health or mental healthcare team. This may include the consideration of whether it will even be possible to structure the local postgraduate training of a non-theological, 'generic' spiritual professional who, by definition, must be a professional worker able to accommodate all faith traditions equally and nonpreferentially. To further ensure equity in the heterogeneous society, for example, candidates from all faith backgrounds would have to be able to access such training, probably on a master's degree level, with some experience and supervision in a clinical setting as part of the requirements. However, the content of such a course should not only constitute a syncretism of all possible different religious teachings, nor should it primarily be informed by only some selected traditions. A postgraduate course on spirituality in a healthcare setting which may, for example, be structured in a medical humanities context, should rather seek to develop a critical understanding of each religious and non-religious position, and should attempt to identify and incorporate possible clinically appropriate processes and applications from each of these traditions.

If a route of postgraduate training is to be considered at all, faculties of humanities and health sciences of local training institutions, as well as relevant professional bodies, may well be able to play the definitive part in a process to define, establish, implement and regulate such a new category of clinical spiritual worker relevant to the current multicultural, multireligious, spiritually diverse SA situation. This will clearly have to include consideration of logistics, cost, blueprinting of the curriculum, and assessment of the eventual outcome and expectations for such a qualification to translate into a viable and employable career option.

\section{Conclusion}

The process of formalising the professional relationship between local psychiatrists and different spiritual professionals or practitioners such as Christian pastoral care workers, traditional healers and other alternative health, cultural or religious practitioners clearly still has some way to go, and has not yet been generally accepted by all psychiatrists in this study sample.

Acknowledgements. This research was supported by the Faculty of Health Sciences of the University of the Witwatersrand, Johannesburg, by awarding two individual grants to the first author during 2009 and 2010.

\section{References}

1. Bhugra D. Psychiatry and Religion: Context, Consensus and Controversies. London: Routledge, 1996. 2. Statistics South Africa. Census 2001: Primary Tables. Statistics South Africa, 2001:24-28. www.info gov.za/aboutsa/people.htm (accessed 17 July 2013).

3. Pew Research Centre. The Global Religious Landscape. Pew Research Center's Forum on Religion \& Public Life, 2012. http://www.pewforum.org/global-religious-landscape.aspx (accessed 17 July 2013)

4. Morris R. Religion and Anthropology. Cambridge: Cambridge University Press, 2006.

5. Loewenthal KM. Mental Health and Religion. London: Chapman \& Hall, 1995.

6. Wig NN. Mental health and spiritual values: A view from the East. Int Rev Psychiatry 1999;11(2):9296.

7. Garroutte EM, Goldberg J, Beals J, Herrell R. Spirituality and attempted suicide among American Indians. Soc Sci Med 2003;56(7):1571-1579. 


\section{$n$

8. Yip K. Taoism and its impact on mental health on the Chinese communities. Int J Soc Psychiatry 2004;50(1):25-42.

9. Dein S. Spirituality, psychiatry and participation: A cultural analysis. Transcult Psychiatry 2005;42(4):526-544. [http://dx.doi.org/10.1177/1363461505058909]

10. Rhi BY. Culture, spirituality, and mental health: The forgotten aspects of religion and health Psychiatr Clin North Am 2001;24(3):569-579.

11. Lapierre L. A model for describing spirituality. J Relig Health 1994;33(2):153-161.

12. Carter JH. Religion/spirituality in African-American culture: An essential aspect of psychiatric care. J Natl Med Assoc 2002;94(5):371-375

13. Chattopadhyay S. Religion, spirituality, health and medicine: Why should Indian physicians care? J Postgrad Med 2007;53(4):262-266.

14. Sexton R, Sorlie T. Use of traditional healing among Sami psychiatric patients in the north of Norway. Int J Circumpolar Health 2008;67(1):135-146.

15. Engel G. The need of a new medical model: A challenge for biomedicine. Science 1977;196(4286):129136.

16. Engel G. Clinical application of the biopsychosocial model. Am J Psychiatry 1980;137(5):535-544.

17. South African Government. Constitution of the Republic of South Africa (Act No. 108). Pretoria South African Government, 1996.

18. Freedom Park Trust. Spirituality and the secular state: A preliminary perspective. Pretoria: Freedom Park Trust, date unknown.

19. Hassim J, Wagner C. Considering the cultural context in psychopathology formulations. South African Journal of Psychiatry 2013;19(1):4-10. [http://dx.doi.org/10.7196/SAJP.400]

20. Rashed MA. Talking past each other: Conceptual confusion in 'culture' and 'psychopathology.' South African Journal of Psychiatry 2013;19(1):12-15. [http://dx.doi.org/10.7196/SAJP.433]

21. Pembroke NF. Appropriate spiritual care by physicians: A theological perspective. J Relig Health 2008;47(4):549-559.

22. De Quincey C. Consciousness from Zombies to Angels: The Shadow and the Light of Knowing Who You Are. Rochester, Vermont: Park Street Press, 2009:27.

23. Josephson AM, Dell ML. Religion and spirituality in child and adolescent psychiatry: A new frontier. Child Adolesc Psychiatr Clin North Am 2004;13(1):1-15. [http://dx.doi.org/10.1016/S10564993(03)00099-3]

24. Verhagen P, Van Praag HM, López-Ibor JJ Jr, Cox JL, Moussaoui D, eds. Religion and Psychiatry: Beyond Boundaries. The World Psychiatric Association's Section on Religion, Spirituality an Psychiatry. New York: John Wiley \& Sons, 2010.

25. Schneiders SM. Religion versus spirituality: A contemporary conundrum. Spiritus 2003;3(2):163185. [http://dx.doi.org/10.1353/scs.2003.0040]

26. Kourie C. Postmodern spirituality in a secular society. In: Du Toit CW, Magson CP, eds. Secula Spirituality as a Contextual Critique of Religion. Pretoria: RITR, 2006.

27. D'Souza R. Incorporating a spiritual history into a psychiatric assessment. Australas Psychiatry 2003;11(1):12-15. [http://dx.doi.org/10.1046/j.1440-1665.2003.00509.x]

28. Blanch A. Integrating religion and spirituality in mental health: The promise and the challenge Psychiatr Rehabil J 2007;30(4):251-260. [http://dx.doi.org/10.2975/30.4.2007.251.260]

29. Pargament KI, Lomax JW. Understanding and addressing religion among people with mental illness. World Psychiatry 2013;12(1):26-32. [http://dx.doi.org/10.1002/wps.20005]

30. Janse van Rensburg ABR, Myburgh CPH, Szabo, CP, Poggenpoel M. The role of spirituality in specialist psychiatry: A review of the medical literature. Afr J Psychiatry (Johannesbg) 2013;16(4):247-255. [http://dx.doi.org/10.4314/ajpsy.v16i4.33]

31. Rumbold BD. A review of spiritual assessment in health care practice. Med J Aus 2007;186(Suppl):S60-S62.

32. Sulmasy DP. A bio-psycho-social-spiritual model of care of patients at end of life. Gerontologist 2002;42:24-33.

33. Coyle BR. Twelve myths of religion and psychiatry: Lessons for training psychiatrists in spiritually sensitive treatments. Mental Health, Religion and Culture 2001;4(2):149-174. [http:// dx.doi.org/10.1080/713685628

34. Lev-Ran S, Fennig S. Points to ponder regarding contemporary psychiatric training in Israel. Is J Psychiatry Relat Sci 2007;44(3):187-193.
35. Bathgate D. Psychiatry, religion and cognitive science. Aust N Z J Psychiatry 2003;37(3):277 285. [http://dx.doi.org/10.1046/j.1440-1614.2003.01178.x]

36. Lakoff G, Johnson M. Philosophy in the Flesh: The Embodied Mind and its Challenge to Western Thought. New York: Basic Books, 1999

37. Janse van Rensburg ABR. A changed climate for mental health care delivery in South Africa. Afr J Psychiatry (Johannesbg) 2009;12(2):157-165.

38. Berg A. Ancestor reverence and mental health in South Africa. Transcult Psychiatry 2003;40(2):194-207. [http://dx.doi.org/10.1177/1363461503402004]

39. Bührmann MV. Western psychiatry and the Xhosa patient. S Afr Med J 1977;51(14):464-466

40. Edwards SD, Grobbelaar PW, Makunga NV, et al. Traditional Zulu theories of illness in psychiatric patients. J Soc Psychol 1983;121:213-221.

41. Griffiths JA, Cheetham RWS. Priests before healers - an appraisal of the isangoma or isanusi in Nguni society. S Afr Med J 1982;62(25):959-960.

42. Cheetham RWS, Griffiths JA. The traditional healer/diviner as psychotherapist. S Afr Med 1982;62(25):957-958

43. South African Medical Association. Bridging the Gap: Potential for a Health Care Partnership between African Traditional Healers and Biomedical Personnel in South Africa. Pretoria: SAMA, 2006.

44. Janse van Rensburg ABR. The role of spirituality in South African specialist psychiatric practice and training. PhD thesis, University of the Witwatersrand, 2010. http://wiredspace.wits.ac.za/ handle/10539/11211 (accessed 21 July 2013).

45. Janse van Rensburg ABR, Poggenpoel M, Myburgh C, Szabo CP. Experience and views of academic psychiatrists on the role of spirituality in South African specialis psychiatry. Revista de Psiquiatria Clínica 2012;39(4):122-129. [http://dx.doi.org/10.1590/ S0101-60832012000400002]

46. Janse van Rensburg B, Szabo CP, Poggenpoel M, Myburgh C. Competence of medical student and residents in psychiatry regarding spirituality, at a South African school of clinical medicine. Int J Psychiatry Med 2013;45(2):175-188.

47. Janse van Rensburg ABR, Poggenpoel M, Myburgh C, Szabo CP. A model for the role of defined spirituality in South African specialist psychiatric practice and training. J Relig Health 2012;53(2):393-412. [http://dx.doi.org/10.1007/s10943-012-9644-3]

48. Kvale S. The qualitative research interview: A phenomenological and a hermeneutical mode of understanding. Journal of Phenomenological Psychology 1983;14(2):171-196. [http://dx.doi. org/10.1163/156916283X00090]

49. Strauss AL, Corbin J. Basics of Qualitative Research. 2nd ed. Thousand Oaks, CA: Sage, 1998

50. Flick U. An Introduction to Qualitative Research. 3rd ed. Thousand Oaks, CA: Sage, 2006.

51. Guba EG. Criteria for assessing the trustworthiness of naturalistic inquiries. Educational Resources Information Centre Annual Review 1981;29(2):75-91.

52. Bulbulia T, Laher S. Exploring the role of Islam in perceptions of mental illness in a sample of Muslim psychiatrists based in Johannesburg. South African Journal of Psychiatry 2013;19(2):52-54. [http://dx.doi.org/10.7196/SAJP.396]

53. Padayachee P, Laher S. South African Hindu psychologists' perceptions of mental illness. J Relig Health 2012;53(2):424-437. [http://dx.doi.org/10.1007/s10943-012-9646-1]

54. Ashforth A. Muthi, medicine and witchcraft: Regulating 'African science' in post-apartheid South Africa? Soc Dyn 2005;31(2):211-242. [http://dx.doi.org/10.1080/02533950508628714]

55. Motlana N. The tyranny of superstition. Nursing SA 1988;3(1):17-18.

56. Janse van Rensburg B, ed. The South African Society of Psychiatrists (SASOP) and SASOP State Employed Special Interest Group (SESIG) Position Statements on psychiatric care in the public sector. South African Journal of Psychiatry 2012;18(3):133-148. [http://dx.doi.org/10.7196/ SAJP.374]

57. South African Government. Traditional Health Practitioners Act (Act No. 35 of 2004) Government Gazette no. 29034, 21 July 2006. Cape Town: Government Printer, 2006.

58. Allied Health Professions Council of South Africa. 2011. http://www.ahpcza.co.za/council struct.htm (accessed 13 March 2011).

59. The Southern African Association for Pastoral Work (SAAP). http://www.saap.za.net/aboutsaap/history (accessed 23 November 2013). 